\title{
Ocorrência de incêndios florestais em Caicó e Natal - RN
}

\author{
Francisco Edislan Gurgel Diógenes ${ }^{1}$, Pompeu Paes Guimarães ${ }^{1 *}$, Rejane Tavares Botrel${ }^{1}$
}

RESUMO: Objetivou-se com este trabalho determinar o período de maior probabilidade de ocorrência de incêndios florestais para Caicó e Natal, ambos situados no Rio Grande do Norte. Para a estimativa foi utilizada a Fórmula de Monte Alegre Alterada (FMA+) aplicada de forma acumulativa aos dados diários de umidade relativa do ar e velocidade do vento medidas às 13 horas, e a precipitação pluviométrica no período compreendido entre 2010 a 2014. Os resultados obtidos demonstram que nos meses contidos entre julho e janeiro foram encontradas as maiores concentrações dos graus de perigo, classificados como altos e muito altos pela metodologia adotada; sendo que os meses de agosto a novembro apresentaram maiores probabilidades de ocorrência de incêndios florestais. Em contrapartida os meses de março, abril e maio, apresentaram a menor probabilidade de ocorrência de incêndios florestais para a cidade de Caicó-RN. Já para a cidade de Natal-RN, os meses que apresentaram uma maior probabilidade de ocorrência de incêndios florestais concentram-se entre outubro e janeiro, sendo que os meses compreendidos no período de fevereiro a setembro apresentam uma maior variação entre as classes de perigo de incêndio. Os meses junho, julho e agosto apresentam menor probabilidade de ocorrência de incêndios florestais.

Palavras-chave: Índices de perigo de incêndios; Fórmula de Monte Alegre Alterada; classificação do grau de perigo.

\section{Forest fire hazard in Caicó and Natal - RN}

\begin{abstract}
The main idea of this work was to determine the period of greatest probability of occurrence of forest fires for Caicó and Natal, Rio Grande do Norte using the Monte Alegre Alterada Formula (FMA+) applied cumulatively to the daily data of relative humidity Air and wind velocities measured at 13 o'clock, and rainfall in the period between 2010 and 2014. The results obtained demonstrate that in the months between July and January were found the highest concentrations of the degrees of danger classified as high and very high ; Being that the months of August to November presented greater probability of occurrence of forest fires. In contrast, the months of March, April and May presented the lowest probability of occurrence of forest fires in the city of Caicó-RN. For the city of Natal-RN, the months that presented a greater probability of occurrence of forest fires are concentrated between October and January. Since the months comprised in the period from February to September show a greater variation between the classes of fire hazard. And the months June, July and August present a lower probability of occurrence of forest fires.
\end{abstract}

Keywords: Fire hazard indexes; Monte Alegre Altered Formula; classification of the degree of danger

\section{INTRODUÇÃO}

A Caatinga, Bioma exclusivo do Nordeste Brasileiro, possui grande diversidade em sua vegetação caracterizada por árvores, arbustos e herbáceas, adaptadas ao clima Semiárido, caracterizado por baixos índices de precipitação pluviométrica, variando entre $300 \mathrm{~mm}$ a $800 \mathrm{~mm}$ por ano (ALMEIDA et al., 2014).

Segundo Machado Neto (2013) é extremamente importante a realização de análises da vegetação arbórea da Caatinga para que seja possível realizar meios de prevenção de incêndios, tendo em vista que a partir da identificação e quantificação das espécies encontradas, é possível estimar a deposição de material por estas, como também sua riqueza de espécies.
Incêndio florestal é aquele que, de origem natural ou criminosa, ocasiona um fogo descontrolado que se expande livremente pela floresta, consumindo seus mais variáveis tipos de combustíveis (SANTOS et al., 2015). Segundo o Artigo 20 do Decreto $n^{\circ}$ 2.661, de 8 de julho de 1998, que regulamenta o Art. 27 do Código Florestal-Lei $\mathrm{n}^{\circ} 4.771$, de 15 de setembro de 1965, os incêndios florestais são entendidos como o fogo não controlado em florestas ou qualquer outra forma de vegetação.

$\mathrm{O}$ controle das informações relacionadas às ocorrências de incêndios registradas reflete grande importância quanto aos mecanismos de prevenção, utilizando os índices de perigo de incêndio para a determinação do período de ocorrência, como também no combate de forma mais eficaz aos 
incêndios florestais. Os índices de perigo de incêndios são calculados por meio de fórmulas específicas, onde cada índice possui suas determinadas variáveis. Estes índices são utilizados para estimar um período de maior probabilidade de ocorrência de incêndio em determinada área. Atualmente, no Brasil, o índice mais empregado é a Fórmula de Monte Alegre (FMA). Este índice em questão é acumulativo e possui como variáveis a umidade relativa do ar medida às 13 horas e o número de dias sem chuva (SOARES, 1972).

Uma atualização do índice de perigo de incêndios, denominado Fórmula de Monte Alegre Alterada $\left(\mathrm{FMA}^{+}\right)$foi desenvolvida para a região central do Estado do Paraná e também tem sido utilizado para calcular o risco de incêndios florestais em outros estados do Brasil. O índice FMA ${ }^{+}$também é acumulativo e diferencia-se do índice FMA em suas variáveis, pois se acrescenta a velocidade do vento, medida às 13 horas (NUNES, 2005).

Alguns índices de perigo de incêndios florestais foram aplicados para correlacionar a ocorrência de incêndios florestais e os focos de calor encontrados para a região do Pantanal sul-matogrossense, sendo escolhido o FMA como melhor índice a aplicar nesta região (SORIANO, DANIEL e SANTOS, 2015). Desta forma, questiona-se se índices de perigo de incêndios desenvolvidos para outras regiões também podem ser aplicados com eficiência para o nordeste brasileiro.

Partindo deste pressuposto, objetivou-se com esta pesquisa estimar o período de maior probabilidade de ocorrência de incêndios florestais baseados na $\mathrm{FMA}^{+}$, para as cidades de Caicó e Natal, ambas no Estado do Rio Grande do Norte.

\section{MATERIAL E MÉTODOS}

\section{Caracterização da área de estudo}

O município de Caicó está inserido na Região do Seridó, parte centro-sul do Estado do Rio Grande do Norte e o município de Natal, pertencente à Mesorregião do Leste Potiguar e à Microrregiação de Natal, deste mesmo estado.

Segundo Köppen e Geiger, a classificação climática de Caicó-RN é BSh, semiárido quente, com temperatura média anual de $26^{\circ} \mathrm{C}$ e índice pluviométrico médio de $696 \mathrm{~mm} \cdot \mathrm{ano}^{-1}$, concentrados entre os meses de fevereiro e maio. A classificação climática de Natal-RN é Aw, tropical, com uma temperatura média anual de $25,8^{\circ} \mathrm{C}$ e índice pluviométrico médio de $1.464 \mathrm{~mm}_{\mathrm{ano}}{ }^{-1}$, concentrados entre os meses de fevereiro e agosto.

\section{Processo metodológico}

O trabalho foi desenvolvido a partir da coleta de dados meteorológicos diários em forma digital, no Banco de Dados Meteorológicos para Ensino e Pesquisa (BDMEP) integrado ao Instituto Nacional de Meteorologia (INMET).

Foram coletados dados diários de umidade relativa do ar e velocidade do vento às $13 \mathrm{~h}$ e de precipitação diária, registrados pelas estações operantes do Seridó - Caicó-RN (OMM: 82690) e de Natal-RN (OMM: 82598), para o período compreendido entre 01/01/2010 e 31/12/2014, correspondendo a 5 anos de observação.

\section{Aplicação da Fórmula de Monte Alegre Alterada $\left(\right.$ FMA $\left.^{+}\right)$}

A Fórmula de Monte Alegre Alterada $\left(\mathrm{FMA}^{+}\right)$foi calculada diariamente, abrangendo o período compreendido entre janeiro de 2010 e dezembro de 2014, para os municípios de Caicó e Natal, Rio Grande do Norte, Brasil.

A partir dos dados obtidos, calculou-se a Fórmula de Monte Alegre Alterada $\left(\mathrm{FMA}^{+}\right)$, índice de perigo de incêndio acumulativo, que tem como variáveis a umidade relativa do ar e a velocidade do vento, medidas às $13 \mathrm{~h}$, conforme Nunes, Soares e Batista (2007).

$$
F M A^{+}=\sum_{i=1}^{n}\left(100 / H_{i}\right) e^{0,04 v} \quad \text { (Equação 1) }
$$

Em que: $F M A^{+}=$Fórmula de Monte Alegre Alterada; $\mathrm{Hi}=$ Umidade relativa do ar (\%), medida às $13 \mathrm{~h} ; n=$ Número de dias sem chuva maior ou igual a $13 \mathrm{~mm} ; v=$ Velocidade do vento $\mathrm{em} \mathrm{m} / \mathrm{s}$, medida às $13 \mathrm{~h}$; $e=$ Base dos logaritmos naturais.

Por ser acumulativo referente à umidade relativa, o índice segue critérios restritivos quanto à precipitação (Tabela 1).

Tabela 1. Modificações no cálculo da $\mathrm{FMA}^{+}$de acordo com a precipitação diária.

\begin{tabular}{cl}
\hline Precipitação diária $(\mathrm{mm})$ & Modificações \\
\hline$\leq 2,4$ & Nenhuma \\
2,5 a 4,9 & Abater $30 \%$ na FMA ${ }^{+}$calculada na véspera e somar $(100 / \mathrm{H}) \mathrm{e}^{0,04 \mathrm{v}}$ do dia. \\
5,0 a 9,9 & Abater $60 \%$ na FMA $^{+}$calculada na véspera e somar $(100 / \mathrm{H}) \mathrm{e}^{0,04 \mathrm{v}}$ do dia. \\
10,0 a 12,9 & Abater $80 \%$ na FMA $\mathrm{FM}^{+}$calculada na véspera e somar $(100 / \mathrm{H}) \mathrm{e}^{0,04 \mathrm{v}}$ do dia. \\
$>12,9$ & Interromper o cálculo $\left(\mathrm{FMA}^{+}=0\right)$ e recomeçar a somatória no dia seguinte. \\
\hline Fonte: Nunes, Soares e Batista (2007). &
\end{tabular}

A classificação do grau de perigo, estimado pela $\mathrm{FMA}^{+}$, baseou-se na escala demonstrada na Tabela 2 . 
Tabela 2. Classificação do grau de perigo de incêndios estimado pela FMA ${ }^{+}$.

\section{Valor de $\mathrm{FMA}^{+}$}

Grau de Perigo
(N) Nulo
(P) Pequeno
(M) Médio
(A) Alto
(G) Muito alto

Fonte: Nunes, Soares e Batista (2007).

\section{Análise Estatística}

Os resultados obtidos de índice de perigo de incêndios médios mensais foram submetidos a uma análise de variância no delineamento inteiramente casualizado. As médias foram comparadas pelo teste de Tukey a 5\% de significância, quando estas apresentaram diferenças estatisticamente significativas.

\section{RESULTADOS E DISCUSSÕES}

Pode-se verificar as estatísticas descritivas diárias da umidade relativa e velocidade do vento, medidas às $13 \mathrm{~h}$, e precipitação pluviométrica para os meses compreendidos entre Janeiro/2010 e Dezembro/2014, para as duas cidades (Tabela 3).

Tabela 3. Estatísticas descritivas das variáveis meteorológicas coletadas, para os municípios de Caicó/RN e Natal/RN.

\begin{tabular}{|c|c|c|c|c|c|c|c|c|c|c|c|c|c|c|}
\hline & & & Jan & Fev & Mar & Abr & Mai & Jun & Jul & Ago & Set & Out & Nov & Dez \\
\hline \multirow{4}{*}{$\begin{array}{l}\text { Umidade } \\
\text { Relativa (\%) }\end{array}$} & \multirow{2}{*}{ Caicó } & Média & 61,7 & 64,8 & 66,4 & 70,1 & 67,2 & 65,5 & 61,4 & 54,0 & 50,6 & 53,1 & 50,9 & 53,5 \\
\hline & & $\mathrm{CV}(\%)$ & 13,4 & 15,0 & 12,0 & 16,4 & 13,8 & 5,2 & 6,6 & 6,9 & 7,2 & 9,3 & 5,0 & 11,7 \\
\hline & \multirow{2}{*}{ Natal } & Média & 78,8 & 79,4 & 79,9 & 81,3 & 82,5 & 84,0 & 84,0 & 81,8 & 81,3 & 79,1 & 77,9 & 78,5 \\
\hline & & $\mathrm{CV}(\%)$ & 4,6 & 4,4 & 5,1 & 5,4 & 6,3 & 6,1 & 6,2 & 6,0 & 5,8 & 3,7 & 4,0 & 4,3 \\
\hline \multirow{4}{*}{$\begin{array}{l}\text { Velocidade do } \\
\text { Vento }(\mathrm{m} / \mathrm{s})\end{array}$} & \multirow{2}{*}{ Caicó } & Média & 1,9 & 1,9 & 1,3 & 1,2 & 1,4 & 1,4 & 2,1 & 3,0 & 3,3 & 2,9 & 2,3 & 2,1 \\
\hline & & $\mathrm{CV}(\%)$ & 0,2 & 0,3 & 0,6 & 0,5 & 0,5 & 0,5 & 0,5 & 0,3 & 0,4 & 0,4 & 0,3 & 0,4 \\
\hline & \multirow{2}{*}{ Natal } & Média & 4,0 & 4,3 & 3,7 & 3,5 & 3,6 & 3,5 & 4,0 & 4,4 & 4,6 & 4,7 & 4,4 & 4,2 \\
\hline & & $\mathrm{CV}(\%)$ & 26,8 & 22,7 & 30,1 & 32,5 & 31,2 & 32,4 & 28,0 & 22,3 & 28,0 & 18,5 & 19,0 & 19,3 \\
\hline \multirow{4}{*}{$\begin{array}{l}\text { Precipitação } \\
\text { Pluviométrica } \\
(\mathrm{mm})\end{array}$} & \multirow{2}{*}{ Caicó } & Média & 2,5 & 2,7 & 3,2 & 5,7 & 3,0 & 1,2 & 0,4 & 0,0 & 0,1 & 0,6 & 0,6 & 0,7 \\
\hline & & $\mathrm{CV}(\%)$ & 39,0 & 91,0 & 45,1 & 55,2 & 78,9 & 52,0 & 99,6 & 150,7 & 124,1 & 186,4 & 183,1 & 119,6 \\
\hline & \multirow{2}{*}{ Natal } & Média & 3,7 & 2,7 & 4,3 & 5,9 & 8,4 & 12,3 & 7,9 & 3,9 & 3,1 & 0,6 & 0,8 & 0,7 \\
\hline & & $\mathrm{CV}(\%)$ & 336,0 & 246,2 & 294,2 & 220,6 & 207,8 & 213,6 & 203,8 & 283,6 & 401,6 & 247,2 & 311,3 & 363,7 \\
\hline
\end{tabular}

Em que: CV(\%): Coeficiente de Variação.

Durante o período de coleta, a umidade relativa, em média, variou de 50,6 a 70,1\%, para os meses de setembro e abril, respectivamente, para o município de Caicó. Já para o município de Natal a variação foi em média de 77,9 a $84,0 \%$ para os meses de novembro e junho, respectivamente. Quanto maior a umidade relativa, menor a probabilidade de perigo de incêndio florestal.

Em Caicó, a máxima velocidade do vento foi encontrada em setembro, registrando $3,3 \mathrm{~m} . \mathrm{s}^{-1}$, e em Natal, a máxima de velocidade do vento ocorreu no mês de outubro, registrando $4,7 \mathrm{~m} \cdot \mathrm{s}^{-1}$. A velocidade do vento, uma variável de propagação irá influenciar na intensidade do fogo, velocidade de propagação e direção do incêndio florestal. Quanto maior a velocidade do vento, maior a probabilidade de perigo de incêndio florestal.

No mês de abril concentrou-se a maior precipitação pluviométrica, em média, $5,7 \mathrm{~mm}$, para Caicó, e 12,3 mm no mês de junho para Natal, reduzindo a probabilidade da ocorrência do incêndio florestal.

Com a aplicação da $\mathrm{FMA}^{+}$nos anos compreendidos entre 2010 e 2014, foi possível destacar dois momentos específicos. (1) No primeiro momento, que correspondeu aos meses de março até maio, observou-se que ocorreu uma maior variação nos índices de perigo de incêndio, ressaltando que os graus de perigo diários foram classificados, em sua maioria, como nulos, pequenos e médios, por influência da precipitação pluviométrica registradas neste período, para o município de Caicó. Já para o município de Natal, observa-se que esta variação se estendeu de fevereiro até setembro, correspondendo a oito meses com a maior presença de graus de perigo de incêndios classificados como nulos, pequenos e médios, também por influência das maiores taxas de precipitação registradas nesse período. (2) No segundo momento, que se estendeu do mês de junho ao mês de fevereiro, pode-se observar uma predominância do índice de grau de perigo tido como muito alto, para o município de Caicó. Isto se deu devido as taxas de precipitação pluviométrica serem menores, representando um menor volume médio total no período estudado, sendo, portanto, considerado o mais seco do ano. Já para o município de Natal a predominância destas classes de perigo concentrou-se no período compreendido entre os meses de outubro e janeiro. 
Desta forma, a Tabela 4 apresenta as estatísticas Natal. descritivas para a $\mathrm{FMA}^{+}$calculadas Para Caicó e

Tabela 4. Estatísticas descritivas para a FMA ${ }^{+}$calculada.

\begin{tabular}{|c|c|c|c|c|c|c|c|c|c|c|c|c|c|}
\hline & & Jan & Fev & Mar & Abr & Mai & Jun & Jul & Ago & Set & Out & Nov & Dez \\
\hline \multirow{3}{*}{ Caicó } & GP & $\mathrm{G}$ & $\mathrm{G}$ & $\mathrm{A}$ & $\mathrm{A}$ & $\mathrm{G}$ & $\mathrm{G}$ & $\mathrm{G}$ & G & $\mathrm{G}$ & G & G & $\mathrm{G}$ \\
\hline & Média & $110,6 \mathrm{ab}$ & $26,1 \mathrm{ab}$ & $21,1 \mathrm{~b}$ & $15,4 \mathrm{~b}$ & $32,6 \mathrm{ab}$ & $44,6 \mathrm{ab}$ & $31,5 \mathrm{ab}$ & $85,3 \mathrm{ab}$ & $127,2 \mathrm{ab}$ & $170,9 \mathrm{ab}$ & $155,8 \mathrm{ab}$ & $185,3 \mathrm{a}$ \\
\hline & $\mathrm{CV}(\%)$ & 119,1 & 98,7 & 91,9 & 148,4 & 154,8 & 108,0 & 39,9 & 27,4 & 26,0 & 33,6 & 75,8 & 84,9 \\
\hline \multirow{3}{*}{ Natal } & GP & $\mathrm{G}$ & $\mathrm{M}$ & $\mathrm{M}$ & $\mathrm{M}$ & $\mathrm{P}$ & $\mathrm{P}$ & $\mathrm{P}$ & $\mathrm{M}$ & $\mathrm{M}$ & G & G & $\mathrm{G}$ \\
\hline & Média & $27,8 \mathrm{abc}$ & $12,1 \mathrm{abc}$ & $13,5 \mathrm{abc}$ & $10,4 \mathrm{bc}$ & $7,9 \mathrm{bc}$ & $3,2 \mathrm{c}$ & $3,8 \mathrm{c}$ & $8,5 \mathrm{bc}$ & $11,5 \mathrm{bc}$ & $31,1 \mathrm{abc}$ & $35,0 \mathrm{ab}$ & $43,0 \mathrm{a}$ \\
\hline & $\mathrm{CV}(\%)$ & 93,0 & 60,4 & 49,9 & 75,9 & 88,7 & 32,0 & 39,6 & 22,6 & 35,6 & 37,6 & 52,8 & 75,8 \\
\hline
\end{tabular}

As médias seguidas por uma mesma letra, em linha, não diferem entre si em nível de $5 \%$ de significância pelo teste de Tukey.

Em que: CV(\%) - Coeficiente de Variação, em porcentagem; GP - Grau de Perigo: N - Nulo; P - Pequeno; M - Médio, A - Alto e G - Muito Alto.

Em relação a $\mathrm{FMA}^{+}$média calculada para Caicó, durante todo ano, pode-se classificar o perigo de incêndio florestal como muito alto, excetuando-se os meses de março e abril, que apresentaram grau de perigo alto de incêndios florestais.

Para o perigo de incêndios florestais de Natal, a probabilidade muito alta ocorreu de outubro a janeiro, e pelo teste de Tukey a 5\% de significância, também não houve diferença entre os mêses de fevereiro e março. Desta forma, o período com menor probabilidade de ocorrência de incêndio florestal seria compreendido entre abril e setembro (sendo classificados como de pequeno e médio grau de perigo).

Tanto para Caicó quanto para Natal no mês de dezembro houve a maior probabilidade de ocorrência de incêndios florestais. Assim, este período sugere que a atenção sobre colunas de fumaça e formas de rápido combate a incêndios florestais devem ser redobradas.

Caicó
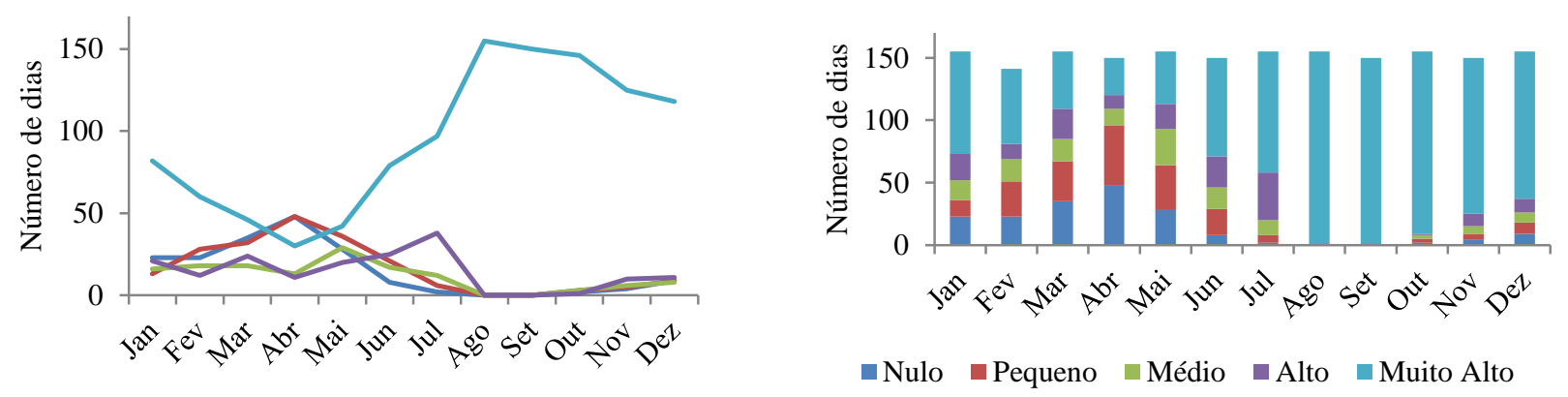

Natal
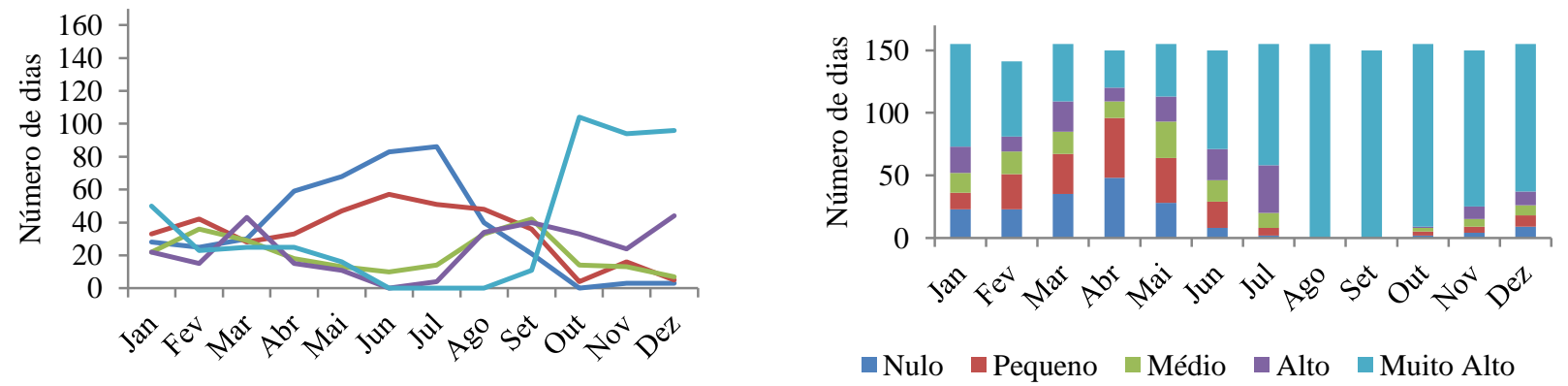

Figura 1 - Comparações entre as classes de perigo de incêndios florestais para Caicó e Natal.

A tendência na classificação do número de dias com probabilidade nula e pequena na ocorrência de incêndio florestal mostrou uma estimativa semelhante para os 12 meses avaliados. Para Caicó houve um aumento a partir de janeiro, com ponto máximo em abril e decresceu até agosto. Para Natal este aumento foi verificado também a partir do mês de janeiro, com seu pico máximo no mês de julho, decrescendo no mês de setembro. As classificações médias e altas também apresentaram uma estimativa análoga a probabilidade de ocorrência de incêndios florestais. 
Houve um predomínio de junho a fevereiro para a classificação muito alta de ocorrência de incêndios florestais para o município de Caicó, e nos meses de outubro a janeiro para o município de Natal, durante este período deverá ocorrer maior vigília por parte dos brigadistas e sistemas de detecção e supressão de incêndios florestais (Figura 1).

Quando se obtém o grau de perigo classificado como Alto ou Muito Alto, a probabilidade de ocorrência de incêndios florestais nesse período são maiores, e o sistema de controle deve estar preparado para rápidas ações, indicando a importância da determinação diária da $\mathrm{FMA}^{+}$(MAIA, MARTOS e BARRELA, 2001).

$\mathrm{Na}$ Tabela 5, pode-se, observar que para a cidade de Caicó 82,7\% dos dias dos meses entre junho e fevereiro apresentaram graus de perigo classificados como alto e muito alto. E apenas $11,4 \%$ dos dias foram classificados com os graus de perigo nulo e pequeno. Para a cidade de Natal 75,9\% dos dias destes meses apresentaram graus de perigo classificados como alto e muito alto. E apenas 14,6\% dos dias foram classificados com os graus de perigo nulo e pequeno.

Tabela 5. Distribuição percentual dos índices de perigo de incêndio florestal diários para os municípios de Caicó-RN e Natal-RN.

\begin{tabular}{|c|c|c|c|c|c|c|c|c|c|c|c|c|c|}
\hline \multicolumn{2}{|c|}{ Grau de Perigo } & Jan & $\mathrm{Fev}$ & Mar & Abr & Mai & Jun & Jul & Ago & Set & Out & Nov & Dez \\
\hline \multirow{5}{*}{ Caicó } & Nulo (\%) & 14,8 & 16,3 & 22,6 & 32,0 & 18,1 & 5,3 & 1,3 & 0,0 & 0,0 & 1,3 & 2,7 & 5,8 \\
\hline & Pequeno $(\%)$ & 8,4 & 19,9 & 20,6 & 32,0 & 23,2 & 14,0 & 3,9 & 0,0 & 0,0 & 1,9 & 3,3 & 5,8 \\
\hline & Médio (\%) & 10,3 & 12,8 & 11,6 & 8,7 & 18,7 & 11,3 & 7,7 & 0,0 & 0,0 & 1,9 & 4,0 & 5,2 \\
\hline & Alto $(\%)$ & 13,5 & 8,5 & 15,5 & 7,3 & 12,9 & 16,7 & 24,5 & 0,0 & 0,0 & 0,6 & 6,7 & 7,1 \\
\hline & Muito Alto (\%) & 52,9 & 42,6 & 29,7 & 20,0 & 27,1 & 52,7 & 62,6 & 100,0 & 100,0 & 94,2 & 83,3 & 76,1 \\
\hline \multirow{5}{*}{ Natal } & Nulo (\%) & 18,1 & 17,7 & 19,4 & 39,3 & 43,9 & 55,3 & 55,5 & 25,8 & 14,0 & 0,0 & 2,0 & 1,9 \\
\hline & Pequeno (\%) & 21,3 & 29,8 & 18,1 & 22,0 & 30,3 & 38,0 & 32,9 & 31,0 & 24,0 & 2,6 & 10,7 & 3,2 \\
\hline & Médio (\%) & 14,2 & 25,5 & 18,7 & 12,0 & 8,4 & 6,7 & 9,0 & 21,3 & 28,0 & 9,0 & 8,7 & 4,5 \\
\hline & Alto $(\%)$ & 14,2 & 10,6 & 27,7 & 10,0 & 7,1 & 0,0 & 2,6 & 21,9 & 26,7 & 21,3 & 16,0 & 28,4 \\
\hline & Muito Alto (\%) & 32,3 & 16,3 & 16,1 & 16,7 & 10,3 & 0,0 & 0,0 & 0,0 & 7,3 & 67,1 & 62,7 & 61,9 \\
\hline
\end{tabular}

Mesmo que as diferenças não sejam tão grandes entre os dois municípios, a superioridade percentual de índices altos e muito altos para Caicó é condizente com sua localização em região semiárida, relativamente mais seca que a região em que está inserido o município de Natal.

Os resultados obtidos estão em conformidade com os estudos de Soares e Santos (2002), Santos, Soares e Batista (2006) e Santos et al. (2015) que concluíram que a estação que apresentou o maior risco de incêndios florestais ocorreu no período entre os meses de julho a novembro. Correspondeu ao inverno e primavera no Brasil, caracterizando-se como a estação seca do ano, onde as taxas de precipitação pluviométrica são mais baixas entre os meses de julho e dezembro, intensificando-se nos trimestres agosto-outubro e setembro-novembro, segundo Lucena et al. (2013).

\section{CONCLUSÕES}

$\mathrm{Na}$ ausência de índices referentes ao perigo de incêndios florestais para a região nordeste do Brasil, o $\mathrm{FMA}^{+}$parece ser o índice que mais se aproxima da estimativa real.

- Os meses compreendidos entre agosto e novembro possuem uma maior concentração dos graus de perigo Alto e Muito Alto, elevando a possibilidade de ocorrência de incêndios florestais, para o município de Caicó. O mesmo pode ser observado para o município de Natal no período compreendido entre os meses de outubro a janeiro.

- Os resultados apresentaram alguma variação (elevado coeficiente de variação) devido ao índice de perigo utilizado ter sido elaborado para uma região diferente da região de estudo, reforçando a necessidade do desenvolvimento de índices de perigo de incêndios próprios para cada região.

\section{REFERÊNCIAS}

ALMEIDA, A. Q. de; MELLO A. A de; DÓRIA NETO, A. L.; FERRAZ, R. C. Relações empíricas entre características dendrométricas da Caatinga brasileira e dados TM Lansat 5. Pesq. Agropec. Bras., Brasília, v. 49, n. 4, p. 306-315, 2014.

ALVES, J. J. A.; ARAÚJO, M. A.; NASCIMENTO, S. S. Degradação da Caatinga: uma investigação ecogeografica. Caatinga, Mossoró, v. 22, n. 3, p. 126-135, 2009.

BRASIL. Decreto n.2.661, de 8 de julho de 1998a. Regulamenta o parágrafo único do art. 27 da Lei $\mathrm{n}^{\circ} 4.771$, de 15 de setembro de 1965 (código florestal), mediante o estabelecimento de normas de precaução relativas ao emprego do fogo em práticas agropastoris e florestais, e dá outras providências. Diário Oficial da União, Brasília, 9 de julho de 1998.

FRANCISCO, P. R. M.; CHAVES, I. de B.; CHAVES, L. H. G.; LIMA, E. R. V. de; SILVA, B. B. da. Umidade antecedente $\mathrm{e}$ índice de vegetação da diferença 
normalizada no mapeamento da caatinga. Agropecuária Científica do Semiárido, Patos, v. 13, n. 2, p. 82-91, 2017.

LUCENA, R. L., FERREIRA, A. M., FERREIRA, H. F. P. A., STEINKE, E. T. Variabilidade climática no município de Caicó/RN: secas e chuvas num arquétipo do clima semiárido do nordeste brasileiro. Climep Climatologia e Estudos da Paisagem, Rio Claro, v. 8, n. 2, p. 67-89, 2013.

MACHADO NETO, A. P. Parâmetros climáticos e da vegetação em áreas de caatinga e cerrado, como base para prevenção de incêndios florestais, sob linhas de transmissão de energia. 118 p. Dissertação (Mestrado em Ciências Florestais) - Universidade Federal Rural de Pernambuco, Recife, 2013.

MAIA, N. B.; MARTOS, H. L.; BARRELA, W. (Orgs.). Indicadores ambientais: conceitos e aplicações. São Paulo: EDUC; COMPED; INEP, 2001.

NOVAIS, D. B.; SILVA, J. M. da; SOUTO, P. C.; SOUTO, J. S.; CAMAÑO, D. Z. Impactos del uso de los incendios en propriedades químicas y físicas de los suelos semiáridos Paraíba. Agropecuária Científica no Semiárido, Patos, v. 13, n. 3, p. 187-194, 2017.

NUNES, J. R. S. FMA ${ }^{+}$- Um novo índice de perigo de incêndios florestais para o Estado do Paraná-Brasil. 150f. Tese (Doutorado em Engenharia Florestal) - Setor de Ciências Agrárias, Universidade Federal do Paraná, Curitiba, 2005.

NUNES, J. R. S.; SOARES, R. V.; BATISTA, A. C. Ajuste da Fórmula de Monte Alegre Alterada $\left(\mathrm{FMA}^{+}\right)$ para o Estado do Paraná. Floresta. Curitiba, v. 37, n. 1, p. 1-14, 2007.
NUNES, J. R. S.; FIER, I. S. N.; SOARES, R. V.; BATISTA, A. C. Desempenho da Fórmula de Monte Alegre (FMA) e da Fórmula de Monte Alegre Alterada $\left(\mathrm{FMA}^{+}\right)$no distrito florestal de Monte Alegre. Floresta, Curitiba, v. 40, n. 2, p. 319-326, 2010.

SANTANA, J. A. S.; ARAUJO, I. M. M. SENA, C. M.; PIMENTA, A. S.; FONSECA, F. C. E. Determinação dos períodos críticos de ocorrência de incêndios florestais na estação ecológica do Seridó, Serra Negra do Norte-RN. Caatinga, Mossoró, v. 24, n. 1, p. 43-47, 2011.

SANTOS, J. F., SOARES, R. V., BATISTA, A. C. Perfil dos incêndios florestais no Brasil em áreas protegidas no período de 1998 a 2002. Floresta, Curitiba, v. 36, n. 1, 2006.

SANTOS, W. de S.; SOUTO, P. C.; SOUTO, J. S.; MENDONÇA, I. F. C. de; SOUTO, L. S.; MARACAJÁ, P. B. Estimativa dos riscos de ocorrência de incêndios florestais no Parque Estadual Pico do Jabre, na Paraíba. Agropecuária Científica do Semiárido, Patos, v. 11, n. 1, p. 80-84, 2015.

SOARES, R. V. Determinação de um índice de perigo de incêndio para a região centro-paranaense, Brasil. 1972. 72 p. Dissertação (Mestrado em Engenharia Florestal) - Instituto Interamericano de Ciências Agrícolasde OEA, Turrialba, Costa Rica.

SOARES, R. V.; SANTOS, J. F. Perfil dos incêndios florestais no Brasil de 1994 a 1997. Floresta, Curitiba, v. 32, n. 2, p. 219-232, 2002.

SORIANO, B. A. M; DANIEL, O.; SANTOS, S. A. Eficiência de índices de risco de incêndios para o pantanal Sul-Matogrossense. Ciência Florestal. Santa Maria, v. 25, n. 4 , p. 809-816, 2015. 